\title{
Comparative Study of Visual \& Auditory Memory between Psychology \& Non-Psychology Students: Testing a Stream Hypothesis
}

\author{
Dr. Rajendra Kumar Sharma ${ }^{1}$, Mr. Vikas Sharma ${ }^{2}$
}

\section{ABSTRACT}

Background and Objectives: The process of retention and storage of any kind of information is known as Memory. Present study was conducted to compare the Visual \& Auditory Short term memory (STM) in Psychology \& Non psychology Students. Materials and Methods: After appropriate consent from students and department. The study comprised of 60 students (30 Psychology, 30 non-psychology/other stream students ) aged 16-20 years of Amity University Gwalior, M.P included ,students having infirmities (Visual or Auditory) were excluded. Reaction time for audiovisual exposures to recalling is noted in all ten subtests. Results: There is a strong difference between the retention and storing capacity of visual STM and auditory STM among both groups. Results: There is a strong difference between the retention and storing capacity of visual STM and auditory STM $(\mathrm{p}<0.001)$ between both groups. The mean reaction time is more for long words/sentences than short words. Short words are remembered more accurately than long words by both groups. Interpretation and Conclusion: The visual STM has a short mean reaction time and more accuracy than auditory STM. STM and working memory plays an important role in the learning processes of both groups of undergraduate students.

Keywords: Auditory Short-Term Memory, Visual Short-Term Memory, Working Memory.

One of the higher functions of human beings is to recall the events which have occurred in the past. The storing and memorizing property of brain is termed as "Memory". So memory can be defined as "the process of retention and storage of any kind of information for short or long periods". The purpose of present study is to compare the two categories of short term memory i.e. visual and auditory on all sub scale P.G.I. memory Scale. Through our study we tried to find out which form of memory is accurate and can be recalled best between two stream (Psychology

\footnotetext{
${ }^{1}$ Associate Professor \& HOD, Department of Clinical Psychology, Amity University Gwalior, M.P, India

${ }^{2}$ Assistant Professor, Department of Psychology, Amity University, Gwalior, M.P, India

*Responding Author
}

Received: December 30, 2016; Revision Received: January 19, 2017; Accepted: January 30, 2017

(C) 2017 Sharma R, Sharma V; licensee IJIP. This is an Open Access Research distributed under the terms of the Creative Commons Attribution License (www.creativecommons.org/licenses/by/2.0), which permits unrestricted use, distribution, and reproduction in any Medium, provided the original work is properly cited. 


\section{Comparative Study of Visual \& Auditory Memory between Psychology \& Non-Psychology Students: Testing a Stream Hypothesis}

\& Other stream). As the development of memory occurs mostly high during the mentioned age group (sixteen to twenty), so the subjects included are undergraduate. Short-term memory has usually been thought of to be primarily an auditory process. Current evidence has shown that short-term memory has the tendency to be a visual procedure as well. In recent years there have been dissimilarities involving the amount of recall ability that visual and auditory short-term memory demonstrates. In view of above consideration, the present study is an attempt to compare the visual \& auditory short term memory in undergraduate students between 16 yrs to 20 yrs age groups \& to evaluate the rapidity and specificity of response of both visual and auditory inputs on ten different domains.

\section{RESEARCH DESIGN AND METHODOLOG}

The study comprised of 60 Students psychology undergraduate and non Psychology students (aged 16 years to 20 years) from Amity University from Department of Behavioral and Allied Sciences. Out of 60 participants, 30 were psychology undergraduates and 30 were other/non undergraduate students. The students were allowed to participate in the study after taking appropriate consent from students; Department concern .Mean age was 16.5 for all 60 students. The students were randomly selected and those having any infirmities were excluded.

Testing Memory - For comparing the visual and auditory short term memory P.G.I Memory Scale were used. It contains 10 subtests. Remote memory, Recent Memory, Mental Balance, Attention and concentration, Delayed recall, Immediate recall, Retention for similar pairs, Retention for dissimilar pairs, Visual Retention and Recognition.

Each student was tested individually. Testing was done in a well illuminated quiet room in AIBAS psychology department. For Remote Memory - items were asked related to student's remote memory. On Recent memory items were related to twenty four hours self chore activity. On Mental Balance students were asked to recite A to $\mathrm{Z}$ or backward counting. For attention and concentration digit forward and digit backward sub tests were used. On delayed recall students were instructed "I am going to read the name of the some objects, listen carefully and when I ask you repeat". List of 10 short words was produced; each word was exposed for $1 \mathrm{sec}$ so total time is 10 sec they were asked to recall for each correct answer 1 mark given. The auditory section immediate recall was tested in same manner by giving short sentences "I am going to read a few small sentences one by one. Listen them carefully because when I am through I would like you to tell me the whole sentences as precisely as you can”. Students were shown 3 long sentences lists. After auditory exposure of each of the auditory lists, the subjects were asked to recall what they remembered and scored as per performance. The procedure was repeated for each student. 


\section{Comparative Study of Visual \& Auditory Memory between Psychology \& Non-Psychology Students: Testing a Stream Hypothesis}

The auditory section verbal retention for similar pairs was tested in same manner by giving short words/pairs "Now I am going to read little small paired word one by one. Listen them carefully because when name one word of pair you will tell the second word of the pair". After auditory exposure subjects were asked to recall and scored as per performance. The procedure was repeated for each student. The auditory section verbal retention for dissimilar pairs was tested in same manner as verbal retention for similar pairs. Here stimulus words are to be presented in the order as mentioned for each of trails.

\section{RESULTS}

\begin{tabular}{|c|c|c|c|c|c|c|}
\hline \multirow[b]{2}{*}{ Subtests } & \multicolumn{2}{|c|}{$\begin{array}{l}\text { Psychology } \\
\text { Students } \\
(n=30)\end{array}$} & \multicolumn{2}{|c|}{$\begin{array}{l}\text { Non-psychology } \\
\text { Students } \\
(n=30)\end{array}$} & \multirow[b]{2}{*}{$95 \%$ CI } & \multirow[b]{2}{*}{$t$} \\
\hline & $M$ & $S D$ & $M$ & $S D$ & & \\
\hline Remote Memory & 7.03 & 0.99 & 3.30 & 1.70 & {$[3.01,4.45]$} & $10.34 *$ \\
\hline Recent Memory & 4.26 & 0.69 & 2.33 & 1.18 & {$[1.43,2.43]$} & $7.72 *$ \\
\hline Mental Balance & 7.83 & 1.05 & 4.26 & 2.18 & {$[2.68,4.45]$} & $8.06^{*}$ \\
\hline $\begin{array}{l}\text { Attention \& } \\
\text { Concentration }\end{array}$ & 23.50 & 3.74 & 15.56 & 5.10 & {$[5.61,10.24]$} & $6.86 *$ \\
\hline Delayed Recall & 7.76 & 0.89 & 4.46 & 1.92 & {$[2.52,4.07]$} & $8.51^{*}$ \\
\hline Immediate Recall & 10.03 & 1.24 & 6.83 & 3.05 & {$[1.99,4.40]$} & $5.31 *$ \\
\hline Verbal Recall & 4.06 & 0.78 & 2.63 & 1.24 & {$[0.89,1.97]$} & $5.33^{*}$ \\
\hline Verbal Retention & 13.16 & 1.44 & 7.6 & 3.33 & {$[4.23,6.89]$} & $8.38 *$ \\
\hline Visual Retention & 11.23 & 1.40 & 7.23 & 2.82 & {$[2.84,5.15]$} & $6.94 *$ \\
\hline Recognition & 7.73 & 0.82 & 6.06 & 1.89 & {$[0.91,2.42]$} & $4.41 *$ \\
\hline
\end{tabular}

Note. $\mathrm{CI}=$ Confidence Interval

$d f=58, * p<0.05$; significant 


\section{Comparative Study of Visual \& Auditory Memory between Psychology \& Non-Psychology Students:}

Testing a Stream Hypothesis

\section{Hypothesis:}

There will be no significant difference on PGI-Memory scores between psychology and nonpsychology students.

Table B, Result of t-test on PGI-Memory scores for both groups

\begin{tabular}{|c|c|c|c|c|c|c|c|c|}
\hline \multirow[b]{2}{*}{ Outcome } & \multicolumn{3}{|c|}{ Psychology Students } & \multicolumn{3}{|c|}{$\begin{array}{l}\text { Non-psychology } \\
\text { Students }\end{array}$} & \multirow[b]{2}{*}{$95 \% \mathrm{CI}$} & \multirow[b]{2}{*}{$t$} \\
\hline & $n$ & $M$ & $S D$ & $n$ & $M$ & $S D$ & & \\
\hline PGI-Memory & 30 & 96.63 & 4.52 & 30 & 60.30 & 9.10 & {$[32.61,40.04]$} & $19.57^{*}$ \\
\hline
\end{tabular}

Note. $\mathrm{CI}=$ Confidence Interval

$d f=58,{ }^{*} p<0.01$

\section{CONCLUSION}

To test the hypothesis an independent samples t-test was conducted. Prior to conducting the analysis, the assumption of normality for distributed difference scores was examined. The assumption was considered satisfied, as the skew and kurtosis levels were estimated at 1.2 and 2.7 respectively which is less than the maximum allowable values for a t-test (i.e., skew $<|2.0|$ and kurtosis < |9.0|; Schmider, et.al, 2010). As displayed in table B, the null hypothesis of equal PGI-memory means was rejected, $t(58)=19.57, p<0.01$ (two-tailed). Thus, mean PGI-memory score $(M=60.30, S D=9.10)$ for non-psychology students is statistically significant lower than mean PGI-memory score $(M=96.63, S D=4.52)$ for psychology students. It is therefore concluded that stream is associated with increasing the PGI-memory in psychology students.

\section{Acknowledgments}

The author appreciates all those who participated in the study and helped to facilitate the research process.

\section{Conflict of Interests}

The author declared no conflict of interests.

\section{REFERENCES}

Alloway TP, Gathercole SE and Pickering SJ. Verbal and visuospatial short-term and working memory in children. Child Development 2006 Nov-Dec;77:6:1698- 1716.

Atkinson RC and Shiffirin RM. The control system of short-term memory. Scientific American 1971 Aug;225(2):82-90.

Bjerklie GL and Harton A. Demographic and intellectual correlates of the short-term memory test. Psycho Reports 1992;70:113-114.

Botvinik M and Plaut DC. Short-term memory for serial order. A recurrent neural network model Psychological Review 2006;113:201-233.

(C) The International Journal of Indian Psychology, ISSN 2348-5396 (e) | ISSN: 2349-3429 (p) | 67 


\section{Comparative Study of Visual \& Auditory Memory between Psychology \& Non-Psychology Students: Testing a Stream Hypothesis}

Daneman $\mathrm{M}$ and Carpenter PA. Individual differences in working memory and reading. $J$ of Verbal Learning and Verbal Behaviour 1986;19: 450-466.

Elizabeth H.A Comparative study of visual and auditory short-term memory.IUSB.Edu/J 5. Luck SJ and Vogel EK. The capacity of visual working memory for features and conjunctions. Nature, PubMed 1997;390:279- 281.

Evans, Hilary and Fontana D.Mode of stimulus presentation and short-term memory efficiency in primary school. British J of Edu Psychology 1980 Nov;50:pt 3,229-35.

Hitch GJ, Towse JN and Hutton U. What limits children's working memory span? $J$ of Experimental Psychology, 2001 Jun;130(2):184- 198.

John W and Hitch GJ. Working memory and children' s mental addition. $J$ of Experimental Psychology, 1997;67:21-38.

Koppitz EM.A visual aural digit span test in elementary school children' s. $J$ of clinical Psychology, 1970; 26:3:349-353.

Nagaich NK. The effect of age and sex on immediate memory span. Asian $J$ of Psychology and Education, 1986;17:1-6.

Shinrigaku K.Some differences between the visual and auditory memories in the short - term memory. PubMed 1990 Apr;61(1):8-14.

Sperling G. The information available in brief visual presentations. Psychology Monographs 1960; 74:1-24.

Susan E,Gathercole SE, Pickering and Benjamin A. The structure of working memory from 4 to 15 years of age. Developmental Psychology 2004;40:2:177-190.

Una MZ,Hutton U and Towse JN. Short-term memory and working memory as indices of children’ s cognitive skills. Psychology Memory 2001;9(4/5/6):383-394.2003. 4.

Visscher KM, Kaplan E,Kahana MJ, Secular R. Auditory short-term memory behaves like visual short-term memory. PLos Biol 2007 Mar;5(3):e56.

How to cite this article: Sharma R, Sharma V (2017), Comparative Study of Visual \& Auditory Memory between Psychology \& Non-Psychology Students: Testing a Stream Hypothesis, International Journal of Indian Psychology, Volume 4, Issue 2, No. 86, ISSN:2348-5396 (e), ISSN:2349-3429 (p), DIP:18.01.029/20170402, ISBN:978-1-365-68609-2 